\title{
El instrumental teórico de Pierre Bourdieu y la influencia tomista en su concepto de habitus
}

\section{Pierre Bourdieu's theoretical instruments and the thomistic influence on his concept of habitus}

Fecha de recepción: 3 de agosto de 2011

Fecha de evaluación: 3 de octubre de 2011 Fecha de aprobación: 10 de octubre de 2011

\author{
Carlos Alberto Cárdenas Serra**
}

\section{RESUMEN}

De acuerdo con la propuesta del título de este ensayo, se pretende aproximar el sentido del habitus bourdeiano al sentido del habitus tomista, no solo por la coincidencia del significante, sino también por la amplia coincidencia semántica, de tal manera que el tecnicismo escolástico de pronto se torna operativo, como si se tratase de un término contemporáneo, arrojando nueva luz sobre el uso bourdeiano, y viceversa. No solo el viejo tecnicismo se enriquece con el de Bourdieu, sino que éste parece necesitado de recuperar la antigua luz de la razón práctica tomista.

Palabras clave: Habitus, campo (social, político, religioso, jurídico), capitales (social, económico, simbólico), intercambio desigual, principio de clarificación.

* Corresponde a un extracto de la investigación "Filosofía iuseconómica tomasiana en diálogo con la filosofía iuseconómica contemporánea".

** Docente e investigador adscrito al Centro de Investigaciones Sociojurídicas Francisco de Vitoria de la Facultad de Derecho de la Universidad Santo Tomás; líder del grupo de Investigación Raimundo de Peñafort; miembro de la Sociedad Internacional Tomás de Aquino; docente-tutor de la Maestría en Derecho Público de la USTA-Konstanz; docente de Fundamentación Filosófica de los Derechos Humanos en la Maestría de Derechos Humanos de la USTA. Correo Electrónico: torreondomingo@gmail.com 


\section{ABSTRACT}

According to the title proposal, this essay intends to bring the sense of the bourdeian habitus nearer to the meaning of the thomistic one, not only due to the coincidence of the signifier, but also taking into account the wide semantic coincidence, in such a way that the scholastic technicality suddenly becomes operational as if it were a contemporary term, shedding new light on the bourdeian use and vice versa. Not only the old technicality is enriched by Bourdieu's one, but this one seems to need to recover the ancient light of thomistic practical reason.

Keywords: habitus, (social, political, religious, legal) field, (social, economic and symbolic) capitals, unequal exchange, clarification principle.

"El habitus es cierta disposición para la operación, difícilmente movible, según la cual alguien se encuentra bien o mal dispuesto y que procede, en parte, de un principio exterior".

Tomás de Aquino (ST, I-II, 49-51)

"Los habitus son "sistemas de disposiciones duraderas y transferibles, estructuras estructuradas predispuestas a funcionar como estructuras estructurantes"

Pierre Bourdieu (El sentido práctico)

\section{INTRODUCCIÓN}

El presente ensayo pretende esbozar una aproximación a la figura intelectual del gran sociólogo contemporáneo Pierre Bourdieu, y al marco para la comprensión de su instrumental teórico, aplicado varias veces en la teoría sociológica de derecho para dilucidar en el campo jurídico los agentes con sus respectivos habitus y los diversos movimientos de capital (social, cultural, simbólico).

Se trata de rastrear las influencias sobre la vida intelectual de Bourdieu para comprender el origen y el significado del instrumental teórico que nos ofrece en sus obras, resultado de su aplicación a la sociología como investigador práctico, de terreno.
Una de las categorías centrales del instrumental bourdeiano es el "habitus", muy útil en el análisis de la dimensión normativa de la sociedad: la moral, el derecho, la religión, la economía, la política, etc.

De acuerdo con la propuesta del título de este ensayo, se pretende aproximar el sentido del habitus bourdeiano al sentido del habitus tomista. No se trata de buscar un concordismo artificial, procurando equivalencias forzadas. El mismo Bourdieu aludió, con sus citas, a su origen aristotélico-tomista ${ }^{1}$ y aceptó que sus comentaristas, como la socióloga argentina Ana Teresa Martínez, con quien cruzara correspondencia, se refirieran expresamente a la utilización de la semántica tomista², lo que sin duda tuvo distintos puentes en su amplia formación filosófica, debida a la Escuela Normal Superior y a la traducción que hiciera del alemán de la obra Arquitectura gótica y pensamiento escolástico, del crítico del arte medieval E. Panofsky.

1 Cuando se refiere en varios lugares de sus obras a la hexis aristotélica y a la definición del habitus, o como cuando, por ejemplo, se apoya directamente en el pasaje de la "disposición", que incluye sus "condiciones sociales" (Bourdieu, 2010: 104). Y cuando invoca el "principio de clarificación" tomista (Bourdieu, 2008: 50).

2 En 1999, envió Bourdieu a la socióloga Ana teresa Martínez una nota aprobatoria del libro relacionado con él, en la que reconoce como fuentes básicas, entre otras, la hexis aristotélica y el concepto de habitus tomista: "Las 'referencias' que usted invoca son siempre (hasta donde yo puedo juzgarlo) a la vez legítimas y pertinentes: ellas aclaran la noción de habitus tal como yo la empleo, sea por contraste, sea por profundización [...]. Creo que su trabajo, por su claridad, su rigor, su maestría, constituye una notable introducción interpretativa" (Martínez, 2007, passim). 


\section{PIERRE BOURDIEU}

\subsection{La importancia de Bourdieu}

\subsubsection{Las influencias sobre Bourdieu ${ }^{3}$}

Para Bourdieu, la sociología debe hacer en algún momento sociología de la sociología, es decir, buscar el retorno al propio investigador y a su universo simbólico, es decir, una especie de reflexividad ${ }^{4}$, no contemplativa de sí mismo, sino aquella que consiste en "objetivar [...] la posición del propio analista en el campo académico y, por extensión, en el campo de poder" (Giménez, 2000: 26). Para lo cual hay que partir del camino formativo que convirtió a Bourdieu en un homo academicus con un raro, para su época, habitus integral que ataba, de manera indisoluble, teoría y praxis. Una exposición de las ideas de este gran investigador impone rastrear sus influjos familiares, académicos y culturales. Solo así tendremos un panorama de su concepción de la sociología y la gradual definición de su sentido práctico y su influjo en el campo de poder.

3 La arquitectura de este acápite está inspirada en algunas fuentes primarias de Bourdieu, como Homo academicus -considerada por él como una especie de biografía intelectual-, Estudiantes y la cultura, La reproducción y La distinción, con la guía indiscutible de Moreno (2006), Martínez (2007), Giménez (2000) y Vázquez (2002).

4 Es esa misma reflexividad de la que habla su maestro Bachelard cuando describe el oficio del filósofo en un constante repliegue sobre sí para romper con los lazos de toda dogmática, preparando, a su vez, la apertura epistemológica y el ejercicio de la libre "razón fronteriza”: “¿Dónde estoy? ¿Quién soy? ¿En qué espacio imaginario me han encerrado mis lazos? ¿Cuál es ese extraño rasgo del pensamiento filosófico que hace sorprendente lo conocido? ¿Cuál es ese extraño camino de los filósofos que en todo punto es encrucijada? El pensamiento filosófico es vacilación continua, sumamente sorda, aun cuando tiene las pomposas seguridades dogmáticas. Incluso cuando avanza, se repliega hacia sí. Se cree el uno y él se rompe... En efecto, si yo me observo, 'yo es otro'. La duplicación del pensamiento es automáticamente desdoblamiento del ser" (Bachelard, 1994: 236-137). Bourdieu, en su autobiografía intelectual, terminará afirmando que la vocación científica implica "ver extraño lo familiar", analogándola a la actitud predicada para el filósofo por Bachelard.

5 Bourdieu (2008: 61) explica cómo el campo universitario reproduce el campo de poder: "El campo universitario reproduce en su estructura el campo del poder cuya estructura contribuye a reproducir su propia acción de selección e inculcación. En efecto, es en y por su funcionamiento en tanto espacio de diferencias entre posiciones $(y$, al mismo tiempo, entre las disposiciones de
Las influencias de Bourdieu se pueden presentar desde tres grandes perspectivas: su vida personal ( herencia familiar, destino y decisiones), su formación académica (la educación superior: inculcación e incorporación, sus lecturas: los gustos) y, por último, la vida de sociólogo práctico (articulación de teoría y praxis).

\subsubsection{Vida familiar y personal}

Tres ámbitos culturales se encabalgan en la "personalidad" de Pierre Félix Bourdieu, nacido en 1930 en Denguin, poblado de los Pirineos Atlánticos: la cultura campesina de los abuelos, la cultura pueblerina de sus padres y su provincianismo cosmopolita. Al parecer, su familia es ejemplo de lo que sucede a la mayoría de las familias campesinas, de recursos limitados, de la Francia de las décadas del treinta y el cuarenta. La crisis económica y la amenaza de la guerra llevan a considerar a la primera generación que los hijos deben estudiar algo y desempeñar algún oficio en los poblados. La segunda generación continúa con el proyecto progresista y apunta a la capital, esperando que la tercera generación se forme en un centro educativo importante y trabaje allí. Este fue el derrotero marcado por las circunstancias a la familia de Bourdieu: de abuelos campesinos a funcionario de pueblo (su padre era el cartero) $y$, de este, a Pierre: filósofo-sociólogo práctico.

Cuando va a estudiar a la capital, no llega como acomodado que puede pagar la manutención, sino como provinciano que debe ser subvencionado de todo a todo, mientras que la mayoría de los compañeros cuentan con posibilidades económicas que les permiten vivir sus estudios con holgura. El creer en especiales dotes naturales no explica por qué son más aprovechados unos estudiantes que otros, a pesar de que todos están a la par en

sus ocupantes) que se lleva a cabo, fuera de toda intervención de las conciencias y de las voluntades individuales o colectivas, la reproducción del espacio de las posiciones diferentes que son constitutivas del campo de poder". 
la salida de la pista de carreras. En Los estudiantes y la cultura, Bourdieu invita al investigador a ver con atención para superar estas creencias:

Creer que se dan iguales oportunidades de acceso a la enseñanza superior y a la cultura más elevada por el hecho de procurar iguales medios económicos a todos los que poseen las "dotes" indispensables es quedarse a medio camino en el análisis de los obstáculos e ignorar que las aptitudes, medidas con arreglo al criterio escolar, denotan, más que dotes naturales [...], una mayor afinidad entre los hábitos culturales de alumno y las exigencias del sistema de enseñanza o los criterios que en él determinan los buenos resultados (Bourdieu y Passeron, 1969: 48).

La herencia cultural heredada es lo que el sistema escolar evalúa realmente. Esto asegura la reproducción de las relaciones sociales en medio de formales ofertas y democráticas oportunidades de acceso a la educación superior. Esto lo llevará a sus posteriores conclusiones sobre la doble arbitrariedad de la acción pedagógica (relaciones de fuerza entre clases y selección curricular) (Bourdieu y Passeron, 1977: 45-50). En La reproducción. Elementos para una teoría del sistema de enseñanza los autores señalan: “Toda acción pedagógica es objetivamente una violencia simbólica en tanto que imposición, por un poder arbitrario, de una arbitrariedad cultural" (Bourdieu y Passeron, 1977: 45).

Bourdieu descubre muy pronto que no es "herede$r o^{\prime \prime}$ de un patrimonio familiar-cultural y lingüístico que lo habilite con la suficiencia esperada para actuar dentro de la prestigiosa institución de educación superior parisina. El sociólogo francés tiene que trabajar el doble y ocultar su mal "gusto" y "maneras" provincianas para encajar en el "estilo de vida" de los "herederos". En la Distinción. Criterio y bases sociales del gusto, define el "gusto" como la

propensión y aptitud para la apropiación (material y/o simbólica) de una clase determinada de objetos o de prácticas enclasadas y enclasantes, es la fórmula generadora que se encuentra en el estilo de vida, conjunto unitario de preferencias distintivas que expresan, en la lógica específica de cada uno de los sub-espacios simbólicos -mobiliario, vestidos, lenguaje o hexis corporal- la misma intención expresiva (Bourdieu, 1991: 174).

En Los estudiantes y la cultura explica cómo se eligen los elegidos: "Los éxitos y los fracasos escolares [...] son en realidad, fruto de orientaciones tempranas propugnadas en el seno familiar [...]. Las desventajas iniciales de los estudiantes de clases inferiores que no fueron víctimas de la eliminación, sufren una evolución en virtud de la cual el pasado social toma la forma de pasivo escolar [...]" (Bouridieu y Passeron, 1969: 40). Y precisa que los hábitos de los estudiantes herederos de una cultura familiar fuerte alcanzan éxito escolar (nivel universitario), y cómo tal triunfo académico no se explica en el dinero que sus familias posean:

Los estudiantes más favorecidos aportan hábitos, modos de comportamiento y actitudes de su medio social de origen que les son enormemente útiles en sus tareas escolares. Pero no sólo eso; heredan saberes y un savoir faire, gustos y un "buen gusto" cuya rentabilidad escolar, por indirecta, no es menos real. La cultura "libre", condición implícita del buen expediente universitario en ciertas carreras, se halla muy desigualmente repartida entre los estudiantes de diferentes categorías sociales sin que la desigualdad de las rentas llegue a explicar tamañas diferencias (Bourdieu y Passeron, 1969: 46).

En realidad, los estudiantes "son sólo formalmente iguales" por "toda una serie de predisposiciones y de saberes previos del medio social al que pertenecen (Bourdieu y Passeron, 1969: 48).

Su provincianismo lo persigue... Su "destino" está señalado por el Estado: ir a filas en Argelia, en donde tiene contacto con el proceso civilizatorio adelantado allí por su madre patria. Puede 
contrastar las culturas e identificar los problemas sobrevinientes de la colonización: aculturación y desarraigo. Situación que es análoga a sus personales vivencias: desarraigo, el campesinocitadinismo gradual de su familia hasta llegar a él: el capitalino primer hombre. En la zona tiene contacto con los militantes que luchan contra la dominación y observa cómo sus discursos doctos reducen la realidad a estructuras lingüísticas y leyes inexorables que los alejan del compromiso que pregonan.

Al regresar a Francia, sólo con su licenciatura en filosofía, sin herencia cultural familiar y sin alcanzar el grado de doctor (algo que nunca buscó), es difícil que consiga trabajo. Raymond Aron, maestro suyo, lo invita a trabajar en su centro de investigación social. Allí el sociólogo francés aplica la filosofía a la realidad educativa francesa y define su vocación de sociólogo. Con el tiempo, Aron, quien le extendió la mano, marxista hasta el tuétano, formado en el mismo centro educativo -pero verdadero heredero de una carga cultural que le aseguró buen "gusto"-, se afilia al antimarxismo y desde las columnas políticas de $L e$ Figaro y L'Express, se convierte en el asesor político de la clase política francesa. Coincidente con el cambio radical de su amigo, Bourdieu, ya con cierto reconocimiento en los ámbitos académicos y sociales, rompe con Aron, y contando con el apoyo económico de varias transnacionales, funda su propio centro de investigaciones y una editorial.

\subsubsection{Su formación académica y lecturas}

Bourdieu es admitido en el centro de educación superior más importante de Francia: la Escuela Normal Superior (ENS), en donde se formaron grandes personalidades, como Durkheim, Sartre, Aron, Merleau-Ponty, Althusser, entre otros. El sociólogo francés se inicia en la fenomenología con Merleau-Ponty, estudia a Husserl y a Heidegger, y por la misma época toma los cursos de Claude Lévi-Strauss sobre sus experiencias etnometodo- lógicas. Aprovecha lo que el entorno le ofrece para su formación filosófica entre los clásicos, los maestros, condiscípulos y coetáneos: la tradición clásica durkheimiana, la fenomenotécnica francesa -filosofía del concepto (Bachelard), filosofía de la experiencia e historia estructural (Koyré)-, el marxismo estructuralista o el de la perspectiva existencialista. Lee a los clásicos del neokantismo de la filosofía de la cultura de Friburgo y de Marburgo (Weber y Cassirer); asume toda la tradición estructuralista francesa desde Saussure y Durkheim, pasando por Piaget, Lacan, Lévi-Strauss y Althusser. $Y$ en la misma perspectiva, revisa respetuosamente la propuesta de Foucault, su compañero en la Escuela Normal Superior. Comparte sus tesis con otros "normaliens": Derrida, Lyotard, Serres y Le Roy Ladurie.

Mientras Francia no le presta atención al movimiento sociológico (no existe este título universitario) y lo ve sólo como un trabajo académico de segunda para los que no se dedican a la filosofía, en Alemania y Estados Unidos es la gran ciencia del momento, plenamente reconocida. Bourdieu, interesado en conocer estas fuentes, traduce y edita lo mejor de la filosofía y sociología germana y anglosajona. Es así como conoce la sociología alemana (la axiología social de Friburgo, la antropología cultural de Marburgo, la teoría crítica de Frankfurt, etc.) y se hace una idea de la evolución de la sociología Norteamericana (el interaccionismo simbólico, la tesis de la desorganización social, la Escuela de Chicago, el funcionalismo que integra la tradición británica y la sociología interpretativa de Geertz). También conoce y crítica los trabajos de sus contemporáneos "posmodernos".

De esta pléyade se destacan como autores clave que marcaron el talante investigativo Bourdeiano los siguientes: Bachelard, quien le presta su enfoque epistemológico de la lógica diluida y da la síntesis plural (Giménez, 2000: 27-29) para romper con las posturas univocistas cerradas (Bachelard, 
1971 $)^{6}$; Merlot-Ponty, quien le presta el método fenomenológico ${ }^{7}$; Lévi-Strauss le presta su experiencia investigativa etno-estructuralista, y de Piaget toma su perspectiva del estructuralismo constructivista genético.

Armado de estas herramientas integradas en un enfoque dialógico de la historia de la filosofía y de la sociología, arremete contra todos los esquemas culturales del momento, que fungen como perspectivas excluyentes y cerradas sobre sí: existencialismo, fenomenología y estructuralismo; $y$, a la vez, rompe con todas las formas de dualismos epistemológicos que tienden a simplificar la realidad en binas del "todo o nada": colectivismo vs. individualismo, subjetivismo vs. objetivismo, materialismo vs. idealismo, relativismo vs. universalismo. Esta manera de pensar marcada por la ruptura está acompañada de una arraigada capacidad integrativa bachelardiana, y se encuentra asociada con la propuesta iconiconológica de Erwin Panofsky, quien en Arquitectura gótica y pensamiento escolástico explica la coincidencia en el "habitus mental" entre arquitectos y teólogos cuando, en catedrales y sumas teológicas, articulan dialógicamente lo diverso y contradictorio en una

6 Precisa Bachelard en otra obra: “En resumen, a cualquier actitud filosófica general se puede oponer, como objeción, una noción particular cuyo perfil epistemológico revela un pluralismo filosófico. Por lo tanto, una sola filosofía es insuficiente para dar cuenta de un conocimiento preciso [...] Dicho de otro modo: cada filosofía sólo pone de manifiesto una franja del espectro nocional, y es preciso agrupar todas las filosofías para obtener el espectro nocional completo de un conocimiento particular" (1984: 47).

7 Merleau-Ponty (2003) explica cómo el sabio no puede seguir creyendo que es capaz de acceder a la naturaleza de las cosas: "El sabio de hoy no tiene ya, como el del período clásico, la ilusión de acceder al corazón de las cosas, al objeto mismo. En este punto, la física de la relatividad confirma que la objetividad absoluta es un sueño, mostrándonos cada observación estrictamente ligada a la posición del observador, inseparable de su situación, y rechazando la idea de un observador absoluto". Bourdieu convencido, como su maestro, de la misma imposibilidad del absolutismo cognoscitivo, nos propone tener en cuenta la doble posición del observador situado: dentro y fuera del objeto. Y afinando esta perceptiva relativa propone que ojalá el observador interno considere su objeto como ajeno y el observador externo tome su objeto como familiar $y$, al mismo tiempo, cada uno de estos observadores debe tomar en su objeto "exótico lo familiar y familiar lo exótico" para superar en los dos casos la confianza en lo evidente (Giménez, 2000: 26). unidad armónica calificada de sublime. En este trabajo de análisis de la arquitectura de la Alta Edad Media y su relación con el pensamiento teológico enciclopédico escolástico, encuentra Bourdieu: a) armonía estructural de aspectos arquitectónicos normalmente incompatibles; b) estética y teología fronterizas, que articulan varios lenguajes con tendencia transdisciplinar, y c) compatibilidad entre arquitectos e intelectuales que comparten un mismo principio de su acción: el habitus que, dejándolos en personal libertad creativa, sin embargo, los identifica como representantes de una manera de pensar y hacer común.

La necesidad de alcanzar la cultura lingüística universitaria no heredada exigida en la ENS y su experiencia en el terreno de la comunidad argelina -proceso civilizatorio vs. discurso militante académico disociado de la existencia agraria- lo llevan a estudiar los problemas de los juegos, las relaciones, las funciones y las gramáticas universales y generativas de los distintos lenguajes, en Wittgenstein, Austin, Jakobson, Lévi-Strauss, Chomsky y otros filósofos del lenguaje.

\subsubsection{Su habitus de sociólogo práctico}

Integrando vida familiar, personal, académica y social, vemos cómo se va construyendo el habitus en Pierre Félix Bourdieu, es decir, lo que es él. No decimos el habitus de alguien, como si fuera una característica externa al sujeto, sino tal y como lo pretendió el sociólogo francés al definir el concepto: "cada uno es un habitus". Esto nos permite ubicar su carácter de homo academicus, que, formado en el más prestigioso centro de educación superior, incorpora como suyos, a su precaria cultura familiar provinciana, los esquemas culturales de los legítimos herederos; esquemas transmitidos a través del "currículo oculto" del medio escolar, mientras que la dimensión de inculcación de la educación recibida se debe a la acción pedagógica del "currículo expreso" a través de la in-formación. 
Este habitus academicus adquirido por Bourdieu tiene dos maneras de expresarse públicamente: la fidelidad a la tradición filosófica francesa del estructuralismo y su talante práxico de ruptura con posturas academicistas que ven el mundo como un conjunto de espectadores sin compromisos y ajenos a los problemas sociales. Respecto de la primera, él inscribe su postura sociológica al nominarla "constructivismo estructuralista", lo que le impone hacer crítica de las posturas heredadas que ven la realidad social reducida a relaciones dicotómicas que desconocen su complejidad, tales como individuo vs. colectividad, realismo vs. idealismo, subjetivismo vs. objetivismo, y le exige, al mismo tiempo, abrirse a la historicidad social, a la vez única y diversa.

Partiendo de la premisa de la imposibilidad del conocimiento absoluto de las cosas y con el fin de alcanzar cierta imparcialidad y criticar lo que normalmente se admite como de sentido común o evidente, consideró que la relación del sujeto con el objeto debía de ser como una especie de objetivación participante:

Homo Academicus es el punto culminante, al menos en sentido biográfico, de una especie de 'experimentación epistemológica' que he comenzado a desarrollar, de manera totalmente consciente, al comienzo de los años sesenta, cuando apliqué a un universo que estudié, de tomar exótico lo familiar y familiar lo exótico: todo ello a fin de explicar lo que, en ambos casos, suele admitirse como evidente [...] (Bourdieu, citado en Giménez, 2000: 26).

Respecto a su talante práxico: el ejemplo de su maestro Lévi-Strauss, su reflexividad respecto de su vida familiar, su contacto con el pueblo Argelino cuando prestó servicio militar, el conocimiento del trabajo del médico militante Franz Fanon, la invitación de Raymond Aron a participar activamente en la investigación sociológica, la posterior ruptura con este y la fundación de su propio centro de investigación social y una editorial para divulgar los resultados, son los hechos que enmarcan su personalidad de sociólogo práctico. Él prefiere este rol al de ratón de biblioteca, pues considera que sus trabajos teóricos no son más que "notas al margen" de sus investigaciones.

Reconocemos que Bourdieu acumuló unos capitales sociales y culturales suficientes para su convertibilidad en capital material (financiación de multinacionales) que le aseguraron el "capital simbólico" necesario para ocupar un puesto en el poder político, no como agente de la contienda que busca acceder a él dentro de ese campo, pero sí, por lo menos, como homo academicus que desde la investigación y posterior crítica social académico-práxica, debida a la divulgación de sus hallazgos a través de su editorial y de los demás medios de comunicación televisivos y de prensa, tuvo la posición privilegiada del que está dentro $y$, a la vez, fuera del campo: como observador externo e interno.

En el siguiente ideograma de relación podemos ver las diferentes influencias sobre Bourdieu:

Como se visualiza en el esquema siguiente, Bourdieu es receptor asimilador de las corrientes más influyentes de la cultura europea durante la primera mitad del siglo XX, sin descartar la continuidad con la escolástica de la Alta Edad Media, cuya savia alimenta la dinámica de la vida intelectual francesa, marcada por el papel tan importante de las primeras universidades, educadoras de la vieja cristiandad. Como lo señala el esquema, hay que distinguir dos facetas claves en la formación bourdeiana: la de la tradición filosófica y la de la tradición sociológica. En la primera es importante destacar el influjo de la fenomenología y el existencialismo, que no borran la presencia de la herencia tomista, por ejemplo, a través especialmente de Panofski y de su conocimiento de la

8 Como él llamaba a sus momentos filosofantes en sus trabajos investigativos. 
historia de la filosofía, que le permitía dialogar con los más destacados neotomistas de su tiempo. Es de notar la importancia del gran epistemólogo Bachelard, que lo vacuna contra los reduccionismos. De la faz sociológica hay que retener el influjo de Ios clásicos de la sociología alamana y francesa, sin soslayar la creatividad de los sociólogos anglosajones. Puesto que Bourdieu encarna al intelectual integral, más allá de la cortedad del especialista, su estructuralismo constructivista interpretativo es el resultado de un pensamiento complejo que dialoga con todos los científicos sociales y se abre a todos los lenguajes científicos. Esta gran "caja de herramientas" teóricas será la que iluminará su faz en la sociología práctica: su proyecto de vida académico y extra-académico.
FAZ FILOSÓFICA

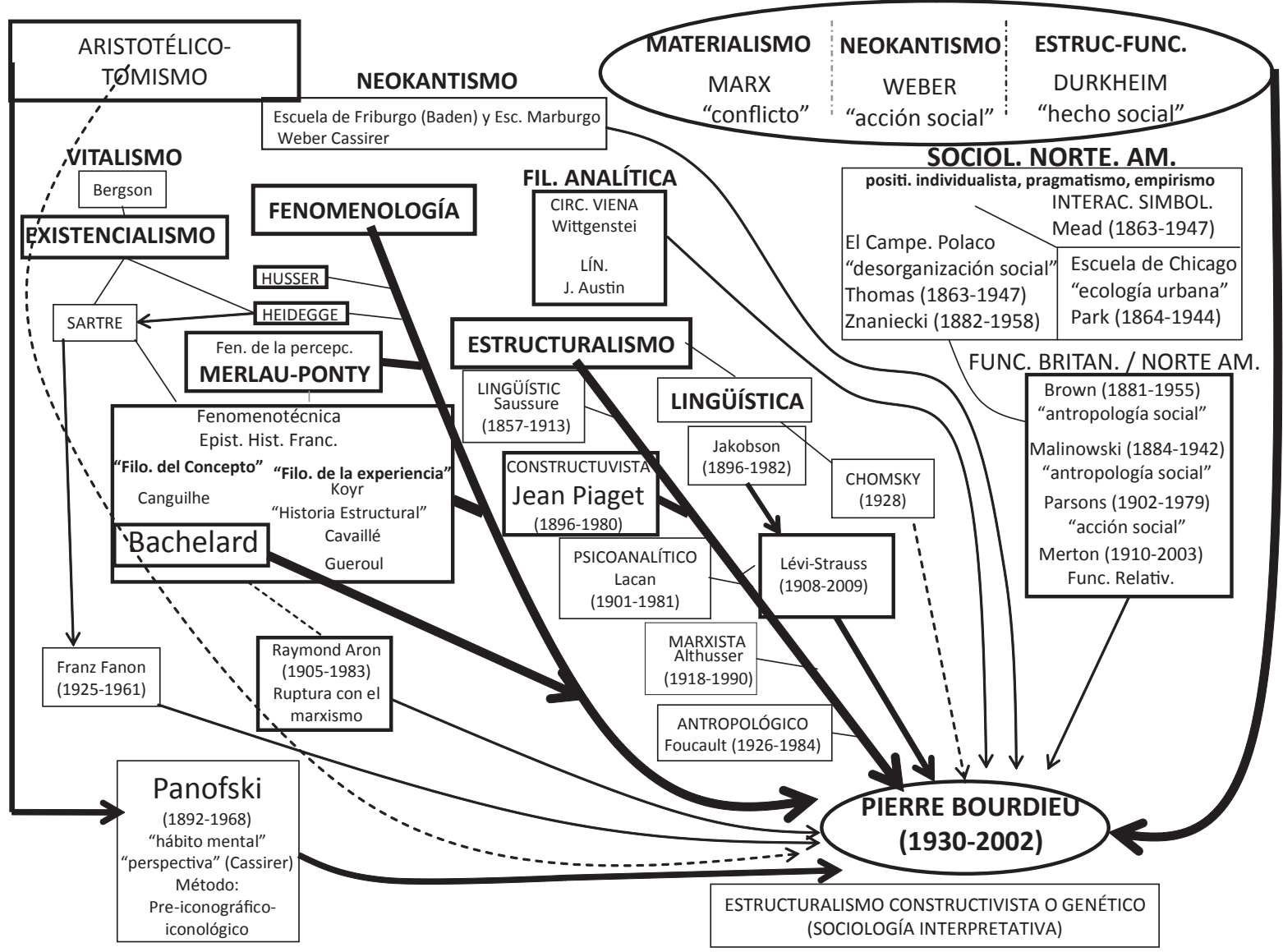

\subsubsection{Influencia de Bourdieu en la época actual}

La vida investigativa de Bourdieu no tenía límites y por eso intentó abarcar diversos objetos de estudio que oscilaron entre la investigación de campo y los aportes a la teoría sociológica. El destacado sociólogo español de la Universidad Pontificia de
Salamanca, Juan Sánchez Horcajo, explica el porqué de su influencia: "En una ya larga trayectoria científica, P. Bourdieu ha realizado amplios estudios de casi todos los ámbitos institucionales, así como destacadas reflexiones sobre la epistemología y la metodología sociológicas" (Sánchez, 1998: 341). Sánchez, además, lo califica de ser un "clásico moderno de la sociología” (Sánchez, 1998: 341). 
Entonces no es raro encontrar en las investigaciones sociológicas las referencias a Bourdieu, aun cuando no se afilien a su perspectiva crítica. Pero sí resulta extraño que sus "notas escritas al margen", incluso cuando no quiso que lo consideraran "filósofo", se convirtieran en categorías libremente utilizadas en investigaciones filosóficas sobre la educación, la política, la economía, el derecho, la ciencia e incluso en temas tan especializados como la literatura, el arte, los gustos y consumos culturales, la dominación masculina y el deporte. Es probable que la tendencia a hacer filosofía desde una determinada ciencia no fuera algo ajeno al verdadero interés investigativo de Bourdieu, pues dijo en Cosas dichas: "La búsqueda sociológica tal como yo la concibo, es también un terreno para hacer lo que Austin llamaba fieldwork in philosophy' (citado en Vázquez García, 2002: 15).

Sus principales categorías de análisis, tales como habitus, campo y capital, por arraigarse en la larga tradición intelectual haciendo que su código básico no sea ajeno, son versátiles, es decir, utilizables por investigadores de diversas ciencias o perspectivas epistemológicas y de todos los tiempos. El mismo Bourdieu no quiso precisar su significado, al intentar resemantizarlas, para no agotar sus posibilidades. La fidelidad a la herencia cultural y la apertura y ruptura con los dogmatismos hermenéuticos aseguró la itinerancia del pensamiento bourdeiano en cualquier investigación en ciencias humanas o sociales, incluso para las nuevas generaciones de los tiempos venideros.

\subsection{El instrumental teórico de Bourdieu}

La constelación conceptual de Bourdieu consta fundamentalmente de tres grandes categorías: habitus, campo y capital; acompañadas de otros conceptos, también importantes, que no estu-

9 "Es verdad que el intervalo de tiempo interpuesto es lo que permite al don o al contra-don aparecer y aparecerse como otros tantos actos inaugurales de generosidad, sin pasado ni porvenir, vale decir sin calculo" (2010: 179). diaremos aquí debido a los estrechos límites que impone el artículo para una revista.

El habitus es el "sentido práctico" o "disposición" para obrar adquirido de manera inconsciente, a través de la "inculcación" y la propia "incorporación", que nos hace competentes para la acción en diversos campos sociales. Se trata de "sistemas de disposiciones duraderas y transferibles, estructuras estructuradas predispuestas a funcionar como estructuras estructurantes" (Bourdieu, 2010: 86). Podría decirse que el habitus es la misma personalidad o carácter, es decir, lo que nosotros hemos hecho de nosotros viviendo, y esta tiene también dos niveles: "el primario, constituido por las disposiciones más viejas o más antiguas [...]. El habitus secundario vendrá a ser el conjunto de disposiciones adquiridas con posterioridad" (MOreno y Ramírez, 2006: 20).

Como vermos en el siguiente ideograma, el campo es el ámbito o escenario de la acción dinamizada por el habitus, dentro del cual los actores sociales luchan por acumular un capital y una posición de poder. Existe un macro-campo denominado "espacio social" o "campo social", compuesto de diversos sub-campos interrelacionaos: económico, político, jurídico, religioso, etc.

El "capital" es el objeto de la lucha dentro del campo y tiene tres dimensiones: social, cultural y económica. La convertibilidad de uno a otro hasta llegar al capital material o económico depende del capital simbólico o acervo moral, reconocido por los agentes del campo, que se materializa en los diversos lenguajes que definen una posición de poder dentro de este.

El origen del concepto de capital simbólico en Bourdieu se encuentra en su crítica a las concepciones económicas que reducen tal actividad social a la dimensión del interés basado en el cálculo. 


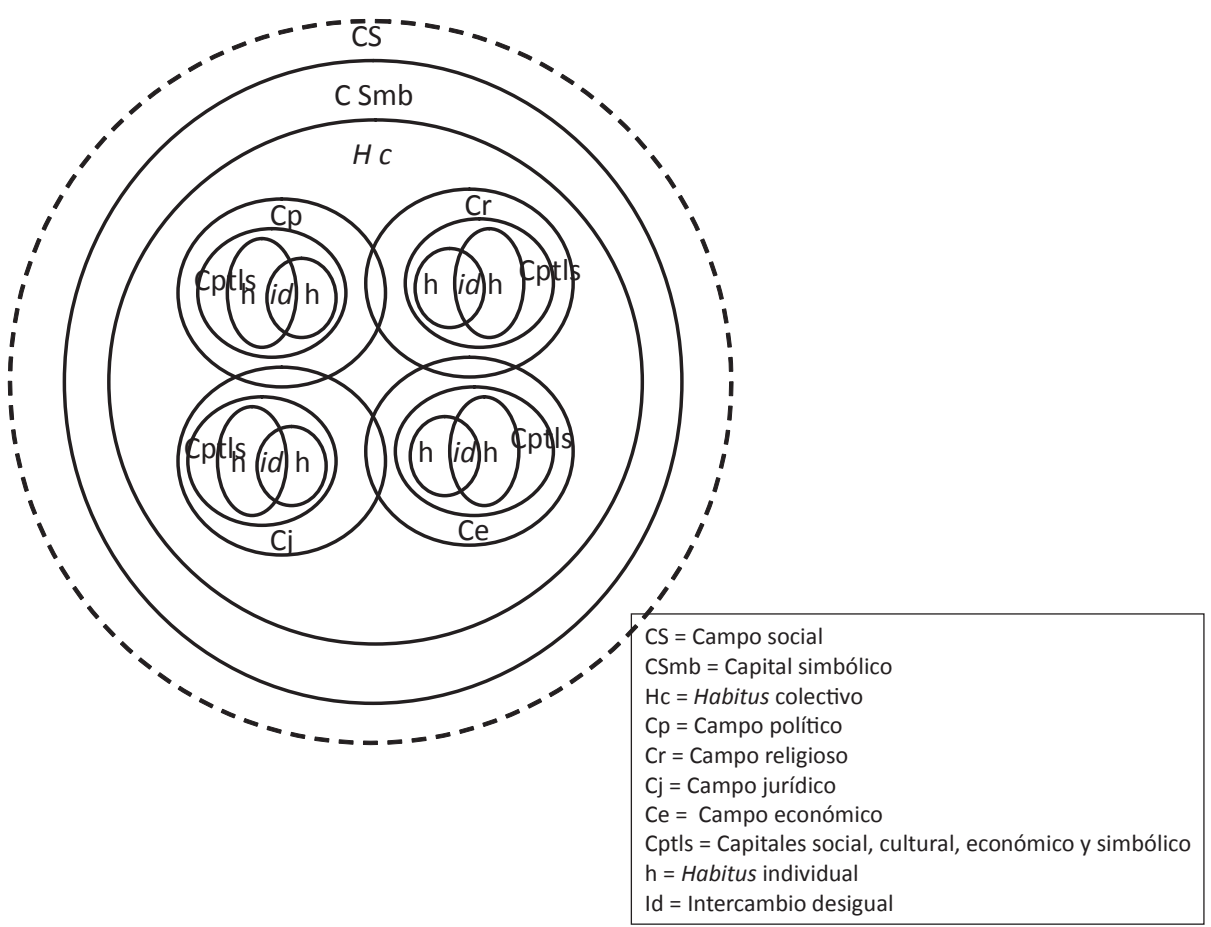

Marx, comentado por nuestro autor, revela cómo los historiadores de la economía contaminan el objeto de estudio usando un lenguaje restrictivo que resulta incapaz de asumir la totalidad de la realidad económica.

Así, se va construyendo un discurso del capital en el que las categorías trabajo-mercancía-dinero impiden el ingreso de otros intereses, que terminan por ser considerados no económicos. La economía de la racionalidad formal del cálculo, tratada por Weber -que supera la basada en la racionalidad material y es sustento del burocratismo privado y público-, afina tal visión unidimensional del mundo económico. El economicismo, fundado en estas dos líneas de análisis, es incapaz de integrar aspectos que normalmente se considerarían ajenos a los estrictos análisis económicos. Bourdieu precisa al respecto: " El economicismo no puede integrar en su análisis y menos aún en sus cálculos ninguna de las formas del 'interés no económico'" (Bourdieu, 2010: 180). La postura del sociólogo francés es que en las comunidades primitivas vigentes la base de la economía no es solamente el interés calculador, sino también el interés no calculador de la mera gratuidad del don. Propone a la economía actual recuperar, para el análisis socioeconómico, la economía del don, que "suspende el ejercicio de la ley del interés" $y$ no necesita de lo "institucionalmente organizado y garantizado", sino tan solo de la reproducción de "relaciones duraderas en tanto fundadas en la naturaleza" (Bourdieu, 2010: 180-179).

Tal mercado consiste en un intercambio "gratuito" de bienes materiales e inmateriales que generan deudas morales convertibles en capital material que, en verdad, encierran una "interesada ficción de gratuidad" (Bourdieu, 2010: 179). Así, el sujeto A que recibe un favor (bien material o inmaterial) de $B$ queda en deuda. A tiene capital simbólico negativo (en su contra) y a favor de B, quien, a su vez, posee capital simbólico positivo, convertible en capital material y redimible contra A. Lo interesante es que A no necesita de contratos, expresos o tácitos, ni de los requerimientos jurídicos 
consiguientes para pagar su deuda, ni tampoco B para cobrarla. Basta con que A tenga una relación simbólica con B. Por ejemplo, en el tráfico de influencias el deudor queda agradecido hasta que puede retribuir de alguna manera sin estar sujeto a plazos y medidas, es decir, al cálculo ${ }^{10}$ : ya sea con un almuerzo, o a servir de "palanca" en el justo momento, o a estar dispuesto para lo que necesite su acreedor, e incluso verse obligado a hablar bien de su benefactor. La prontitud del pago libera psíquicamente de la deuda. Para desarrollar esta economía del don, nuestro autor observó cómo en las comunidades estudiadas se "prestaban la mano" para trabajos que beneficiaban a un miembro del grupo o a toda la comunidad y, con esto, se generaban deudas no materiales, sin embargo convertibles. El don no se refiere, como hemos visto, a la reverencia que se le tiene a alguien, sino a esa parte de la economía olvidada, propia de la crematística primera que se da en la familia: la gratuidad.

El doble aporte de Bourdieu es a la epistemología de la economía y a la sociología de la economía. Para la primera, precisa la superación de la visión del objeto monotética descuidando la politética (Bourdieu, 2010). Y para la segunda trata la recuperación de la economía olvidada del don, que es perfectamente reconocible en las sociedades modernas. En las micro-relaciones económicas, por ejemplo, se materializa en capitales simbólicos que aseguran cierta subordinación de un agente económico a otro mientras se cobra la deuda. Tal "cobro", que implica su convertibilidad, no es expreso y se hace siempre de manera indirecta. En las macro-relaciones económicas se aseguran posiciones de poder y subordinación frente a los deudores: el gobernante prefiere ser amado, honrado, reverenciado, etc. Bourdieu, como vemos, no separa economía y poder, al contrario,

10 En Colombia el "almuerzo" es una de las monedas más aceptadas en la "economía del don". Se podría tomar la frase de Lukács, citada por Bourdieu, para decir que el contra-don del "almuerzo" hace parte del "verdadero suelo de nuestra vida" (2010: 180). considera los campos económico y político interdependientes.

La "profesionalización" de los agentes del campo económico, que genera división del trabajo entre comerciantes (activos buscadores de lucro) y consumidores (actores pasivos dentro del campo), impone deudas de gratuidad identificables en reglas de ingreso, de acción y de respeto entre los negociantes profesionales del comercio. Principios sobre libre competencia limitada, el de la buena fe en los negocios y la "affectio societatis", base de la constitución de las sociedades mercantiles, parten de esa gratuidad del don entre los agentes del campo económico.

No obstante, el consumidor no queda excluido del campo. Su papel, hasta ahora desorganizado, tiene aspectos de la misma economía del don, por ejemplo: el mercadeo, que se basa en la propaganda, apela a los "sentimientos" de respeto por calidades, marcas, precios, etc., deudas de fidelidad de los consumidores esperadas por los comerciantes.

En los últimos tiempos, y con la crítica al consumo en masa que da origen a sociedades de consumo irracional, se apela a la organización de los consumidores no profesionales del comercio en grupos de presión, para que aseguren un papel político dentro del campo económico y reivindiquen sus derechos dentro de una filosofía del consumo racional.

Este pasaje de la "economía del don" en la obra de Bourdieu es importante para entender también cómo surgen los conceptos de capital social y capital cultural, haciendo estallar la tradicional concepción de economía del cálculo, base teórica de la actual economía de mercado posindustrial.

A Bourdieu se le debe la recuperación de una ética en la economía que supera las éticas sin moral de las concepciones de Marx y Weber. No se trata 
de una sistemática de la ética con pretensiones universalistas, pero sí es una micro-ética surgida de la praxis social, revelada por el sociólogo francés. Autores contemporáneos y posteriores se inspiraron seguramente en esta perspectiva de la economía, que recupera, además, lo que estaba en latencia en la filosofía de la economía desde Aristóteles: superación de la tensión entre economía familiar vs. crematística segunda. El sociólogo francés ve la práctica económica como un "hecho social total", no reducido a la banca, la empresa y el mercado. Incluye también la familia, el Estado, la escuela, los sindicatos, las asociaciones, etc. (Bourdieu, 2001: 15).

De tal modo, se advierte a las claras que la inmersión de la economía en lo social es tal que, por legítimas que sean las abstracciones operadas en función de las necesidades del análisis, hay que tener nítidamente presente que el verdadero objeto de la verdadera economía de las prácticas no es, en última instancia, otra cosa que la economía de las condiciones de producción y reproducción económica, cultural y social, es decir, el objeto mismo de la sociología en su definición más completa y general (Bourdieu, 2010: 26).

\subsubsection{Relaciones entre habitus, campo y capital}

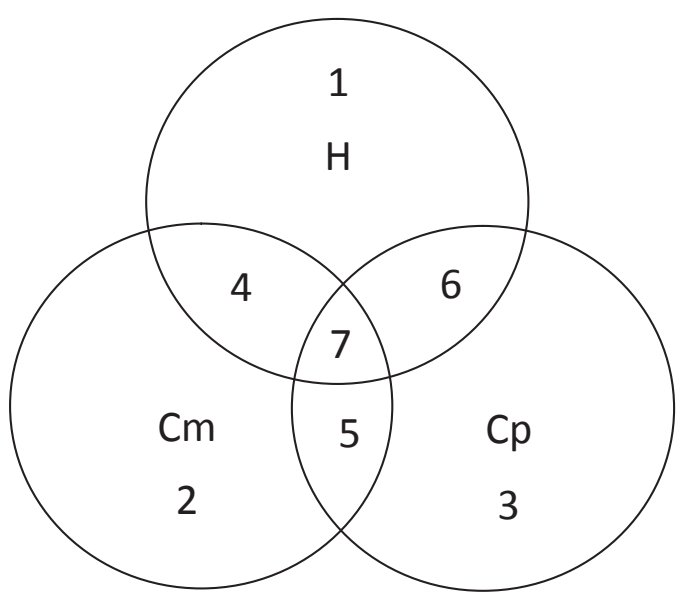

$\mathrm{H}$ = habitus: disposición estable para actuar de una determinada manera, reproduciendo un estándar o transformándolo.
$\mathrm{Cm}$ = campo: ámbito de acción de contenido cultural, social o económico, en el que se cruzan diversos intereses colectivos.

$\mathrm{Cp}$ = capital: "haber" cultural, social o económico que instrumenta las disposiciones de los habitus.

El habitus fuerte hace más competente para definir los roles en un campo determinado.

A mayor acumulación de capital el campo se hace más amplio.

El habitus refuerza la "acumulación" de capital y viceversa.

El habitus dispone a "acumular" capital para afrontar los desafíos del campo. La amplitud "cámpica" expresa la acumulación de capital y amplía las posibilidades creativas del habitus. A más, más. A menos, menos.

\subsubsection{Importancia del concepto de habitus en la sociología bourdeiana}

Un sujeto, gracias al habitus, puede actuar de manera pasiva en varios campos sin especializarse $y$, al mismo tiempo, de manera activa especializando su rol en un determinado campo. La unidad del estilo de vida de un grupo o clase apunta a un habitus de grupo o clase conformado, a su vez, por habitus homólogos convergentes (Bourdieu, 2010: 90). Cada habitus individual tiene tanto de diverso como de homólogo frente al habitus colectivo al que pertenece. El radio de independencia frente a la colectividad está medido por el dominio y conciencia del aspecto diverso del habitus individual. $\mathrm{Y}$ el aspecto creativo del mismo, dentro del radio de acción de la libertad que parte de su diversidad de lo común, se potencia con la confrontación del acontecimiento por parte del individuo en una determinada situación. Y si su respuesta es satisfactoria para él, esta resulta acumulación que favorece el patrimonio del habitus colectivo. Esta capacidad de hacer cosas nuevas con herramien- 
tas prácticas viejas le permite a Bourdieu definir el habitus como "arte de la invención" (Bourdieu,
2010: 90). Visualicemos esto a través del siguiente ideograma:

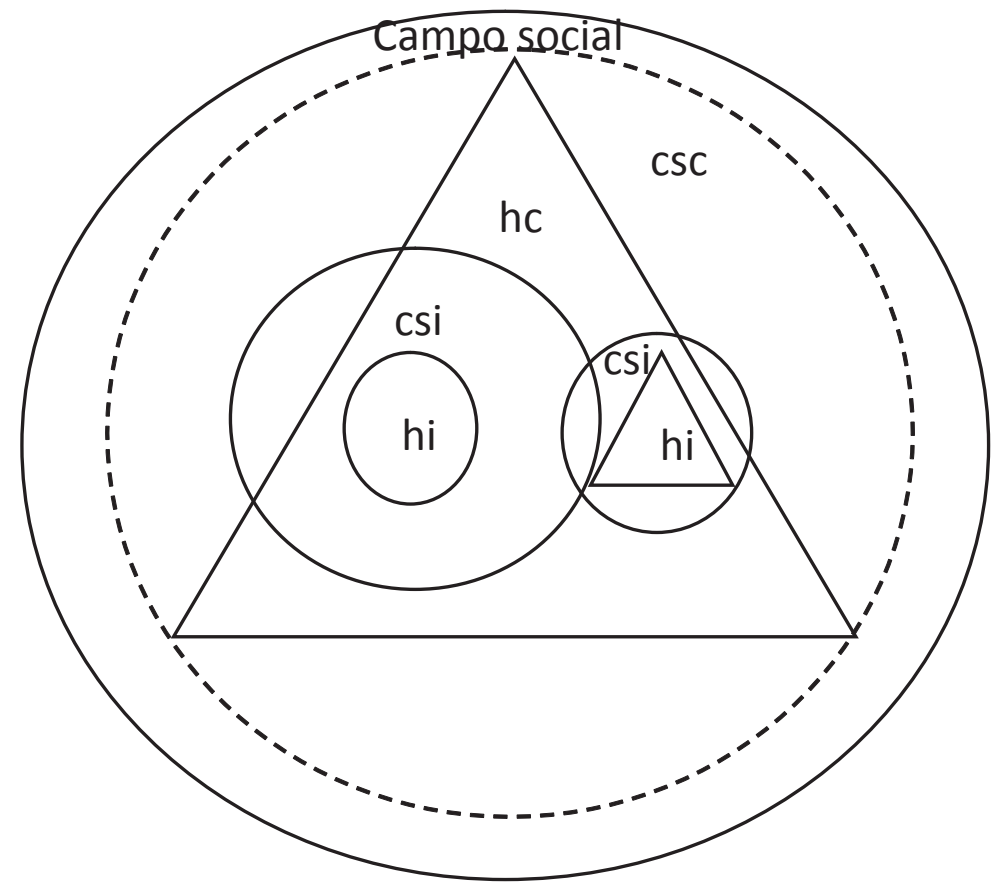

El habitus, colectivo o individual, es el que asegura la presencia constante del pasado en el presente y proyecta el futuro, materializado en esquemas que rigen toda práctica, superando en su capacidad ordenadora e institucionalizante a las normas o reglas explícitas ${ }^{11}$. Las leyes actúan sobre la mera exterioridad, no como el habitus, que, desde dentro, es decir, desde el mismo sujeto, resulta más eficaz en las relaciones de dominación. Si el habitus está enriquecido por una herencia cultural fuerte, se asegura mayor acumulación de capital en un determinado campo y, al mismo tiempo, mejor posición dentro de las relaciones de poder o dominación. Solo el homo academicus que ha

$11 \quad$ Al respecto precisa Bourdeu: "Producto de la historia, el habitus origina prácticas, individuales o colectivas, y por ende historia, de acuerdo con los esquemas engendrados por la historia; es el habitus el que asegura la presencia activa de las experiencias pasadas que, registradas en cada organismo bajo la forma de esquemas de percepción, de pensamientos y de acción, tienden, con más seguridad que todas las reglas formales y todas las normas explícitas a garantizar la conformidad de las prácticas y su constancia a través del tiempo" (2010: 88). hecho una "sociología reflexiva y dialéctica", es decir, que ha sabido ver y prever las acciones de dominación en un determinado campo, es el Ilamado a adelantar las acciones liberadoras o emancipadoras. Hay que investigar la intención política respecto de la educación como instrumento eficaz de introyección del habitus colectivo.

El habitus, como "sentido práctico", recoge en Bourdieu toda la carga semántica de la antigua sabiduría práctica llamada por los griegos frónesis y por los latinos prudencia. La prudencia individual asegura la mejor resolución en situación, tomando, entre otros aspectos ${ }^{12}$, la experiencia adquirida. Opera de acuerdo a la madurez alcanzada por el sujeto. A nivel societario, la madurez colectiva se traduce en un sentido práctico colectivo que

12 En la tradición filosófica tomista se consideran estos ocho elementos del aparato prudencial: memoria de las experiencias, inteligencia, consulta, sagacidad, razón, providencia, circunspección, precaución. 
asegura ciertos comportamientos colectivos en determinadas situaciones que comprometen a la comunidad en su bienestar. Así, el sentido práctico clásico tiene en su seno el sentido objetivado como inseparable aspecto prudencial. Después de que la virtud de la prudencia desaparece, sus partes se separan y cumplen distintas funciones en la vida práctica. Bourdieu relaciona el sentido común con el sentido práctico y el sentido objetivado: "Uno de los efectos fundamentales del acuerdo entre sentido práctico y el sentido objetivado es la producción de un mundo de sentido común, cuya evidencia inmediata se duplica por la objetividad que asegura el consenso sobre el sentido de las prácticas y del mundo, es decir la armonización de las experiencias" (Bourdieu, 2010: 94). El sentido común, como la facultad de juzgar razonablemente según el buen juicio de las personas, no arraiga en la naturaleza humana, sino en las regularidades, que siendo productoras del habitus, dan origen a todas las conductas "sensatas" en un determinado campo social (Bourdieu, 2010: 90-91).

\subsection{Aportes de la teoría de Bourdieu a la teoría del derecho}

\subsubsection{Bourdieu y los teóricos del derecho}

En Homo academicus Bourdieu muestra cómo el campo de las facultades de derecho es el lugar de una incansable contienda de poderes que se desenvuelve en torno al prestigio social-intelectual y el poder científico-teórico como extremos de la lucha entre filosofías o teorías del derecho: iusnaturalismo y iuspositivismo, o realismo jurídico e idealismo jurídico, o subjetivismo jurídico y objetivismo jurídico, etc. Inspirada en esta obra de Bourdieu, la jurista Ángela Santamaría adelantó una investigación en la que pretendió demostrar cómo en Colombia "las prácticas científicas jurídicas [...] están atravesadas por el conflicto de clases y la lucha entre facultades" (Moreno y Ramírez, 2006: 103).
Bourdieu, al interpretar la realidad social, intentó referirse a todos los campos que, interactuando, la componen: el político, el religioso, el económico, el jurídico, etc. Esto hizo que su sociología penetrara, como visor amplificador de la realidad, en los discursos de las diversas ciencias y aun en la filosofía. El jurista Carlos Morales de Setién Ravina, al introducir el opúsculo bourdeiano: "Elementos para una sociología del campo jurídico", considera que "la fuerza crítica de Bourdieu es impresionante y se extiende como magma fluido y líquido a una multitud de sujetos de estudios", entre ellos, el derecho como "racionalidad formal".

Habría dos posiciones frente a la interpretación de la sociología jurídica de Bourdieu: la que la considera sociología interpretativa, que ubicaría al sociólogo francés entre las actuales posturas del "positivismo suave" hartiano, el positivismo "naturalista" dworkiniano o el "no positivismo" alexeyano. Sería un Bourdieu que no tendría reparos en considerar al juez como el protagonista del campo jurídico, con argumentos de integración débil entre derecho y moral (Hart-Dworkin) o integración conceptual necesaria entre estos órdenes normativos (Alexy).

La otra postura interpreta la teoría de Bourdieu como una "sociología jurídica 'sistemática'". Así, el jurista Diego Eduardo López Medina considera que los "trabajos de Bourdieu, Teubner y Luhman son todos esfuerzos dirigidos hacia el entendimiento sistemático del derecho" y pide que ojalá se contrastaran estos "modelos" con la "teoría sistemática de Walerstein" (López Medina, 2000: 10-11). Se trataría no de un estructuralismo constructivista, sino de una versión del "sociologismo de los sistemas". Bourdieu no estaría de acuerdo con la rotulación de su perspectiva de la sociología, porque él ve cómo el concepto de autorreferencia de las "estructuras legales" confunde "las estructuras puramente simbólicas (el derecho propiamente dicho) y las instituciones sociales que la producen". Lo que, para el sociólogo francés, coloca la 
"teoría de los sistemas" en el "marco ideal para la representación formal y abstracta del sistema jurídico" (Bourdieu, 2000: 159).

\subsubsection{Propuestas innovadoras de Bourdieu}

\subsubsection{Superación de la tensión entre formalismo e instrumentalismo}

En Elementos para una sociología del campo jurídico, Bourdieu inicia con una precisión epistemológica: hay que distinguir entre "ciencia del derecho" y "ciencia jurídica" (Bourdieu, 2000: 155-156). La primera tiene por objeto la crítica de la razón jurídica en la segunda. Esto quiere decir que la "ciencia del derecho" ve el derecho de los juristas y la jurisprudencia como instrumentos de dominación.

El sociólogo francés precisa que la postura que se refiere a la "ciencia del derecho" es externalista e instrumentalista y cae en el reduccionismo que comprende el derecho como "un reflejo o instrumento al servicio de los dominadores" (los marxismos) (Bourdieu, 2000). La "ciencia jurídica", por su parte, se reduce a una posición meramente internalista que afirma la "autonomía absoluta de la forma jurídica con relación al mundo social" (Ios formalismos kelsenianos).

Si visualizáramos el asunto tendríamos verdaderas relaciones de exclusión: los "internalistas" pretenden ser los únicos llamados a "decir" el derecho y a hablar de él, cerrándose a toda crítica posible del exterior, lo que los habilita para considerar que la "ciencia del derecho" externalista no sabe de lo que está hablando porque confunde el fenómeno jurídico con el ejercicio del poder y, en consecuencia, con la política. Mientras tanto, la postura crítica de los "externalistas" consideraría tal dogmatismo como una confirmación de la existencia de una "ideología" propia de la "clase" dominante.

Bourdieu no trata de conciliar las posturas como si se tratara de juntar dos esferas hasta encontrar un punto intermedio. Al contrario, ve que los discursos internalista y externalista "ignoran de manera común la existencia social de un universo relativamente independiente de las demandas externas [...] al interior del cual se produce y se ejerce la autoridad jurídica [...] cuyo monopolio corresponde al Estado" (Bourdieu, 2000: 158). Estas posturas extremas no se percatan tampoco de que las "prácticas y discursos jurídicos" son "el producto del funcionamiento de un campo" (Bourdieu, 2000: 159). La superación de este antagonismo entre formalismo e instrumentalismo con la noción de "campo" es el primer aporte de Bourdieu.

Aclarada esta posición epistemológica dentro del "estructuralismo constructivista", Bourdieu pasa a zanjar el viejo debate entre iusnaturalismo y iuspositivismo, es decir, se introduce en el "campo jurídico" y hace su análisis del lenguaje jurídico, no sin antes describir su funcionamiento: a) división del trabajo: lucha por el monopolio a decir el derecho, lo que asegura la especialización de los profesionales y la gradual exclusión de los profanos, la separación entre sentencias e instituciones y la independencia del sistema de normas frente a las relaciones de fuerza (Bourdieu, 2000: 160-162); b) el establecimiento del monopolio: delimitación del "espacio judicial", "neutral", definición del sistema de principios de visión y división ("reglas del juego"), es decir, separación entre la visión vulgar y la visión experta, previsibilidad y calculabilidad de un "derecho racional", constancia y homogeneidad de las disposiciones jurídicas ( habitus) de los jugadores legítimos dentro del campo jurídico; c) el poder de nombrar: el proceso representa "una puesta en escena" en la que los actores del "campo jurídico" persiguen que la autoridad judicial "diga qué es el derecho". El escenario de las facultades de derecho tiende a presentar a las comunidades "académica" o "hermenéutica" como aquellas autoridades investidas con un "poder de nombrar" análogo al de los jueces que, incluso en forma de doctrina, puede influir en la sentencia (Bourdieu, 2000: 196-201); d) la 
fuerza de la forma: el trabajo jurídico no es más que "actividad de formalización" de "agentes formalizadores" (Bourdieu, 2000: 202-205).

\subsubsection{Apertura semántica del término "jurídico" que asegura la relación moral y derecho}

Los Sociólogos Álvaro Moreno y Ernesto Ramírez, en Sociología del campo jurídico en Colombia, precisan cómo en la terminología bourdeiana el término "jurídico" tiene realmente un significado más amplio, "sin circunscribirlo al campo lingüístico del derecho". Bourdieu, "más bien, usa esta palabra para designar todo lo que es percibido, recibido y vivido como obligatorio, todo lo que se disciplina y normaliza siempre donde permanecen los rituales y códigos que observan la prevención y los riesgos de transgresión" (Moreno y Ramírez, 2006: 197).

La tendencia, hasta Hart, es a separar la moral del derecho y a considerar que estos dos órdenes normativos estaban especializados y no había ninguna relación entre ellos. Bourdieu supera este debate entre los que propugnaban por una separación y los que pretendían una unión débil o meramente conceptual. Así, el "poder de nombrar" no se circunscribe a los juristas y se puede hablar de una "gramática jurídica", un "código jurídico", producto de una "codificación" accesible a todos, porque "nadie está excusado de ignorar la ley lingüística, que tiene su cuerpo de juristas, los gramáticos y sus agentes de imposición y control" (Bourdieu, citado en Moreno y Ramírez, 2006: 37). Si no se diera esta posibilidad "descodificadora", nadie acataría las normas jurídicas.

\subsubsection{Los desarrollos de Rémi Lenoir}

El profesor de sociología de la Universidad de París I y director del Centro de Sociología Europeo, Rémi Lenoir, ha desarrollado la sociología jurídica de Bourdieu con fines de clarificación y aplicación del legado del gran sociólogo francés. El doctor en sociología Álvaro Moreno, coordinador de
Investigación del Doctorado en Derecho de la Universidad Santo Tomás, nos presenta los aportes de Lenoir: a) las conductas sociales obedecen más a las regularidades que a las reglas jurídicas; $b$ ) de la interiorización de la regla dentro del habitus depende la obediencia y la eficacia de la misma (legitimidad-creencia); c) la certeza del derecho depende de la explicación y el entendimiento de las prácticas sociales y su relación con las reglas; d) superación del lenguaje cosificado para legitimar acciones: superar máximas como: "la ley es ley" (Moreno, 2010).

\section{TOMÁS DE AQUINO}

\subsection{Las dimensiones sintáctica y semántica}

\subsubsection{El "habitus" tomasiano}

\subsubsection{Contexto doctrinal}

Dentro de la obra de casi 11 millones de palabras del Aquinate, el lugar donde se ocupa de manera sistemática del "habitus" es en las cuestiones 49 a 54 de la Prima secundae (I-II) de la Suma teológica, con un total de 25 artículos, en cuya secuencia se estudian seis grandes problemas: la naturaleza del habitus, el sujeto, la causa, el aumento, la corrupción y disminución y la distinción de los hábitos.

El tratado del habitus tiene como contexto la teoría del los "actos humanos" y las "pasiones" o emociones que favorecen su realización o la bloquean. Tomás propone una teoría de la "inteligencia emocional", como se dice hoy, de acuerdo con la cual la razón práctica no solamente dirige la voluntad, sino que regula la fuerza "pasional" que debe proporcionarle dinamismo. Pero la razón volitivo-pasional no puede reducirse a actos aislados erráticos, sino que debe generar tendencias estables hacia fines valiosos. Por ello, se pasa al problema del habitus, condición necesaria para poder hablar luego de los tipos de "habitus" que son los dinamismos positivos, entendidos como 
las "virtudes" (fuerzas morales humanizantes), y los dinamismos negativos, que son los "vicios" (fuerzas deshumanizantes). Después se hablará de la ley, instrumento externo de intención educativa, enderezada a asegurar "hábitos" personales y colectivos positivos, frenando los "hábitos" viciosos $\mathrm{o}$ antisociales.

La doctrina tomista de los hábitos tiene trascendencia antropológica no solamente porque explica el dinamismo de la vida personal (manera de "llegar a ser"), sino porque es la base de la interpretación tomista de la cultura como conjunto de industrias, instituciones y valores estables, decisivos a la hora de comprender e identificar las distintas maneras de existir colectivamente en las diversas etapas históricas.

\subsubsection{Fuentes del tratado del habitus en Tomás de Aquino}

El tecnicismo filosófico-teológico habitus es tomado por Tomás de Aquino de una prolongada meditación que venía especialmente desde Aristóteles (en la Categorías, en la Metafísica, en la Ética a Nicómaco y en la Política), continuada por los medievales, teniendo en cuenta a San Agustín, sin descartar los aportes árabes y judíos del siglo XII. Los cristianos del siglo XIII, por tanto, reciben una compleja herencia, aprovechada de manera original por el Aquinate, con la mediación enciclopédica de su maestro Alberto Magno.

Tomás recibe a Aristóteles con los ricos aportes hermenéuticos no cristianos y los articula con los aportes patrísticos, a través de la síntesis agustiniana, y teniendo en cuenta la síntesis pluralista albertina, sin desdeñar las reflexiones de los grandes teólogos cristianos del silgo XII (Hugo de San Víctor, Pedro Lombardo, Pedro Abelardo...). Atendió igualmente las exposiciones de otro magnífico maestro del siglo XIII: Alejandro de Hales. No obstante, es claro que prefirió atenerse a las tesis centrales de su maestro, una de las cuales afirmaba la naturaleza "cualitativa" del habitus.
Tomás estaba enterado de cuanto los griegos, los romanos, los cristianos, los árabes y los judíos venían diciendo acerca de la centralidad del habitus en la vida personal y en la vida colectiva, pero, a imitación de Alberto, consideraba que el status quaestionis fundamental como punto de partida había que referirlo a los discursos aristotélico y agustiniano. El "estado del problema" en esas dos fuentes primarias fue lo que más pesó en el tratamiento teórico tomasiano de los hábitos y en el desarrollo doctrinal a lo largo del recorrido histórico del "tomismo".

\subsubsection{Naturaleza del habitus}

En su reflexión acerca de la naturaleza del habitus, Tomás retoma, con Aristóteles, la idea de clasificar las distintas especies en diez "categorías" o diez formas de afirmar (predicar) algo de un sujeto, teniendo en cuenta que se necesita un ser fundamental o radical del que se pueda hablar y en el cual los seres secundarios puedan tener ser. Existen seres que existen en sí mismos y otros que, sin los primeros, quedan "colgados de la brocha", no pueden existir en sí. A los seres que existen en sí mismos se los llamó "substancias" y a los que no, "accidentes". Las substancias no solo existen en sí, sino que en ellas existe lo restante. A las substancias les corresponde la función de permanecer en síy de permanecer "sub", debajo de las demás realidades.

Tomás analiza al habitus y descubre que no puede existir sin "substancia" a la que pertenezca, en la que se exprese. Recorre entonces los "accidentes" aristotélicos: cantidad, cualidad, relación, tiempo, espacio, posición, acción, pasión, hábito, y nota que el Estagirita ha utilizado en las Categorías el mismo significante (hábito) tres veces y con distinto alcance: como uno de los nueve accidentes y en sentido extrínseco (cap. 9); como una de las clases de "cualidad" (cap. 8) y como una de las "poscategorías" o "pospredicamentos" (cap. 15). 
Tomás tiene en cuenta los tres lugares de la obra aristotélica y descubre que el habitus categorial, que procede del verbo habere ('tener' o 'poseer'), constituye esa gran clase de seres en la que entran todos los dispositivos naturales (escamas, plumas, uñas...) que permiten a los entes orgánicos prolongarse en el medio ambiente sin sufrir daño, o todos los dispositivos artificiales que el hombre tiene o posee (vestido, techo, artefactos, armas, instrumentos de producción...) para asegurar su supervivencia individual o social. El habitus como especie de la categoría "cualidad", en cambio, es una calificación intrínseca, que no procede simplemente del habere, sino del reflexivo se habere: hallarse, encontrarse, estar, modo de ser como disposición del sujeto. En cuanto al habitus poscategorial, proviene del habere universal, que abarca toda forma de "poseer": las disposiciones, las virtudes, el conocimiento, la cantidad, las partes del cuerpo, las relaciones, las cosas, etc.

La cualidad es el accidente que modifica o configura la substancia en sí misma, haciéndola ser y aparecer de distintos modos. Mientras la cantidad hace extensa la substancia, la relación le permite tener nexos o conexiones con otras substancias; el tiempo mide su devenir, el espacio la ubica, etc.; la cualidad la transforma desde dentro y la caracteriza mediante propiedades distintivas. Alberto Magno había definido la cualidad como el "accidente que completa y perfecciona la sustancia, tanto en la existencia como en la operación" (Carrasquilla, p. 103).

Tomás maneja la división de la cualidad en cuanto especies, en el orden que Aristóteles le había dado en el capítulo 8 de las Categorías: a) habitus y disposición; b) potencia e impotencia; c) pasividad y modificación recibida; d) forma y figura. Reconoce que hay otras modalidades cualitativas, pero que pueden reducirse a las señaladas. La primera especie afecta al sujeto según su naturaleza; la segunda, como sujeto de actividad u operación; la tercera lo afecta en cuanto sujeto capaz de ser influido o alterado y la cuarta lo hace desde el punto de vista cuantitativo, en cuanto sujeto tridimensional.

El habitus, pues, es una cualidad estable, enraizada en el sujeto, por la cual este se halla permanentemente bien o mal dispuesto según lo que le conviene a su naturaleza ("hábito entitativo": salud, inteligencia, enfermedad) o a su acción ("hábito operativo": virtud, vicio, ciencia, sabiduría, habilidad técnica, etc.). Marca distintiva de las dos clases de habitus es que consisten en formas de "bien" o de "mal" (salud y enfermedad; virtud y vicio, etc.). Al relacionar el habitus con los "actos humanos", Tomás se propuso ante todo construir una teoría de los habitus operativos. Estos se pueden distinguir según las potencias que activan y perfeccionan: intelectuales (ciencia, sabiduría, prudencia, arte...), del apetito sensitivo (fortaleza, temperancia), del racional o voluntad (justicia). Al mismo grupo del habitus pertenece la "disposición", que carece de la estabilidad o arraigo del primero y puede perderse con facilidad, pero a fuerza de ejercitación y repetición puede convertirse en hábito.

El habitus cualitativo exige las mediaciones del habitus categorial. Se trata de un equilibrio en forma de espiral que se va ampliando: 


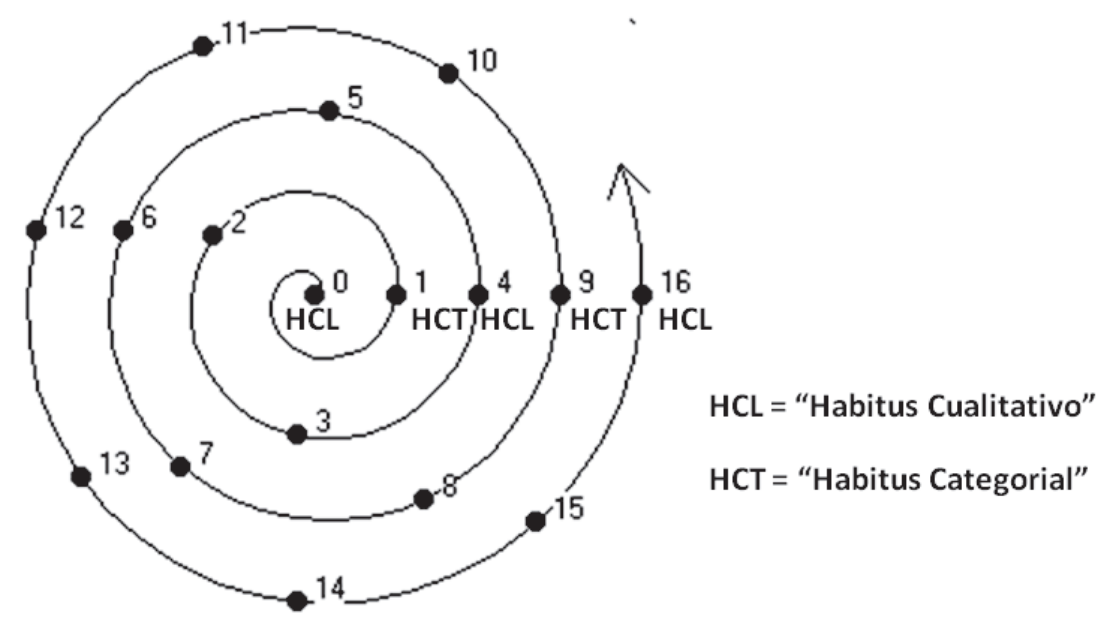

El "habitus categorial" asegura la operatividad (eficacia) del habitus cualitativo a través de la acumulación en la dimensión de la acción del hacer. El habitus cualitativo me capacita para adquirir o crear cosas. Luego de adquiridas o creadas, estas me cualifican categorialmente. Lo mismo se puede decir de la dimensión de la acción del obrar, pues las cosas acumuladas, tanto materiales como del espíritu, reeducan al sujeto.

Los dos tipos de habitus se co-implican y son interdependientes. La primacía del uno sobre el otro puede llevar a la desestructuración psíquica del sujeto: primacía del tener sobre el ser y, con ello, a las diversas formas de alienación: perder la voluntad en otra voluntad, perder el fruto del trabajo, quedar sometido a las exigencias de la máquina, quedar sometido a los desafíos cibernéticos, quedar sometido al mercado de cosas innecesarias, etc.

El remplazo del ser por el tener, que conlleva la desvalorización del "yo", asegura la eficiencia de la convivencia a través de los hábitos de autodomesticación promovidos por los gobiernos de tendencias totalitarias que esperan que los sujetos funcionen como el robot perfecto del "mundo feliz" o la "naranja mecánica" luego del experimento de Ludovico. El "tener" que ha sustituido el "ser" hace creer al sujeto que actúa con libertad y que puede decir, tras cada supuesto, "éxito": "iyo me hice a mí mismo!".

\subsubsection{Habitus categorial y habitus cualitativo $^{13}$}

El habitus categorial como tener o poseer cumple una función instrumental o medial frente al habitus cualitativo. Este ordena el entorno vital y va acumulando en él "cosas a la mano", utensilios, herramientas, es decir, útiles que ayudan a cumplir las disposiciones estables habituales. Se trata de facilitadores de la disposición operativa que indican, por su forma y finalidad factiva, que "están al servicio" de la voluntad constante del sujeto. Las cosas a la mano, propias del habitus categorial, pasan a ser reveladoras del habitus cualitativo: lo que colecciona el asesino en serie, lo que se guarda por previsión, etc.

Entre los habitus en sentido categorial como útiles o utensilios hay que contar las cosas que constituyen las industrias, ámbito de la cultura que comprende a cuanto es objeto de apropiación para la vida cotidiana, desde los medios de vida disponibles, hasta las formas de hacer (técnicas y tecnológicas). Desde qué comer, cómo comer

13 ST, I-II, 49, 1. 
hasta qué vestir, cómo vestir, en qué desplazarse y cómo desplazarse. Desde la moda hasta las técnicas de construcción; desde los utensilios hasta los instrumentos de la guerra.

El habitus categorial implica haber superado la cosa natural y haberla transformado, infundiéndole "espíritu humano". El habitus categorial es espíritu objetivado, capaz de indicar, en todo momento, "para qué sirve", al servicio de qué disposición operativa o fáctica se halla. Las recetas culinarias, los vestidos, los tipos de armas, los adornos, etc., están señalando los "hábitos" cualitativos a que corresponden: disposiciones alimentarias, vestimentarias, estéticas... No siempre las formas de habitus categorial son originadas por las necesidades de los habitus cualitativos. Muchas veces los "habitus" cualitativos son resultado de la educación para el manejo de artefactos. Es decir, como cualidad, es "cierta disposición que se añade" a la sustancia "y la modifica" (Gilson, 2002: 330). Aprender a comer o a vestir determina los platos o a adaptarse a modas vestimentarias, lo mismo que el adiestrarse en manejar determinadas armas tiene como consecuencia generar hábitos operativos que someten la constans voluntas a los imperativos de los utensilios.

\subsubsection{Hábitos entitativos y operativos ${ }^{14}$}

Por razón del sujeto en que se hallan, los hábitos son entitativos (ST, I-II, 51, 1) u operativos (ST, I-II, $55,4)$. Los primeros modifican la substancia individual y disponen al sujeto bien o mal en cuanto a la realización de su propio ser. Los segundos afectan las facultades que impulsan la acción, especialmente la inteligencia y la voluntad.

Los hábitos entitativos son el "haber" constitutivo del ente en cuanto especie y en cuanto existente individual. Si ese "haber" innato original es el que suponen los constituyentes de la especie, el ente

14 Conceptos desarrollados en Grennier (1952: 175). estándar posee el patrón regulador común adecuado. Pero como no se da el ente estándar sino como soporte modificado por la individuación, la realización entitativa de cada uno puede resultar afectada negativamente o distorsionada desfavorablemente (ST, I-II, 51, 1).

Específicamente, en el ser humano se ha de suponer equilibrio orgánico, equilibrio sensitivo, equilibrio psíquico, capacidad reactiva y adaptativa, capacidad de crecimiento y desarrollo, salud integral, inteligencia, capacidad cognoscitiva, etc. Pero cada sujeto o ente individual presenta variaciones de distinto tipo que pueden favorecer o entorpecer la realización de la substancia individual.

En terminología moderna, la "ontogénesis" o desarrollo individual "recapitula" la "filogénesis" o historia de la especie, como repetía Haeckel (Aubert, 1987: 167), pero no la reproduce de manera uniforme, como si se tratase de copias. La "ontogénesis", por efecto de las herencias recibidas y el medio vital, conlleva variaciones de los hábitos de la especie. En otras palabras, el "genoma humano", como mapa estándar de la especie, guía la comprensión del "haber" humano frente a los mapas de otras especies, pero el "genoma personal" introduce elementos determinantes de la historia familiar.

Volviendo al principio: los "hábitos entitativos" son los radicales de los "hábitos operativos" (ST, I-II, 50, 3 ad $2 \mathrm{~m}$ ). El equilibrio psíquico, el temperamento, la salud, la belleza, la fealdad, la raza, etc. condicionan de tal manera las disposiciones adquiridas o "hábitos operativos" que estos se hacen más o menos fáciles de adquirir, más o menos estables, más o menos productivos. Los "hábitos operativos" de la inteligencia teórica y práctica dependen de un cociente intelectual suficiente, que es dotación entitativa básica (quod natura...). Los “hábitos operativos" de los dinamismos morales dependen de un "apetito racional" o voluntad sostenida que es resultado de los "hábitos entitativos" equilibrio psí- 
quico y físico, incluso contra "hábitos entitativos" desfavorables: enfermedad, debilidad. El principio tomista: operatio sequitur ese ('la operación sigue al ser') se aplica perfectamente en este caso. El obrar se funda en la estructura del ente.

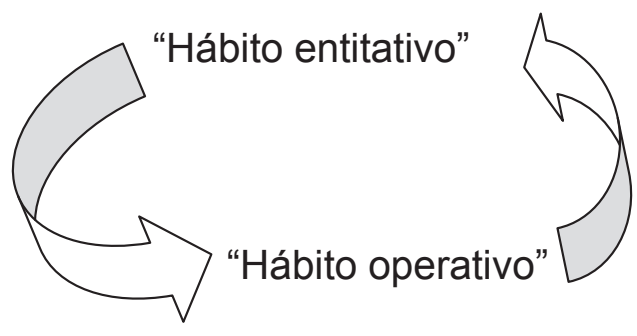

El esquema visualiza la interdependencia de los "hábitos": los "entitativos" aseguran la orientación de los "operativos"; pero estos pueden influir en el fortalecimiento de los "entitativos". Una inteligencia y una voluntad entrenadas en la práctica de la "temperancia", de la "fortitudo", de la "justicia", la "prudencia", pueden volver sobre la dotación entitativa (impulsiva, oréxica, instintiva) y reconducirla para alcanzar o recuperar la salud o para aprovechar ventajosamente la debilidad o la enfermedad, como analizaba Karl Jaspers, refiriéndose a su propio estado enfermizo crónico.

Tomás de Aquino lleva su idea del habitus, especialmente el "operativo", a la vida colectiva, que es asegurada como bona vita por el habitus social de la "justicia general" (de todos los convivientes) y de la "justicia legal" (del legislador, gobernante y ciudadanos que cumplen las leyes), cuyo objeto es la construcción de un habitus de conservación del todo y de distribución para todos.

También en este caso es preciso retener la distinción entre hábitos entitativos y hábitos operativos. Estos hábitos propios del sujeto colectivo están condicionados por los "hábitos" constitutivos de la historia y las realidades relacionales que dan origen a una sociedad: pueblos originarios, raza, industrias, territorio, valores, creencias, conflictos históricos de consecuencias estables, constantes económicas, formas heredadas de inclusión y de exclusión. De ahí que el Aquinate dé importancia a la forma del "régimen político" supeditado al ser de cada pueblo, es decir, a los "hábitos entitativos" originarios que dejan su impronta colectiva.

Tomás se refiere a la prudencia política (ínsita en la costumbres del pueblo), legislativa (que debe respetar las costumbres), gubernativa (que no puede desconocer la índole de la comunidad); formas del hábito operativo de la prudencia colectiva distinta de la prudencia personal y de la prudencia familiar. La prudencia es habitus de la razón que dirige la acción, es decir, de la razón práctica enfrentada a los desafíos de la situación concreta, tanto del sujeto individual como del sujeto colectivo.

Los hábitos operativos colectivos, que se traducen en paz, seguridad, amistad, unidad, justicia, bien común, no dependen de la mera coacción ni de la mera buena voluntad. Son inestables y cambiantes según los hábitos entitativos que conforman el ente social, susceptibles de variación según las fuerzas e influencias sociopolíticas endógenas y exógenas que reacondicionan los componentes originarios y van determinando la gobernabilidad. De ahí que Tomás prefiera el régimen mixto, abierto a la participación de todos, contra los regímenes de exclusión o privilegio: la monarquía, la aristocracia, y especialmente contra los riesgos de la tiranía, régimen fijista y totalitario, que impide la flexibilidad exigida por el vaivén de intereses de las realidades relacionales.

\subsubsection{Realización humana ${ }^{15}$ y habitus operativo}

Cada sujeto que obra, en lugar de consistir en una razón y una voluntad puras e indeterminadas, se halla influido en sus acciones por maneras de ser y por disposiciones permanentes propias, adquiridas por educación o por reiteración

15 ST, I-II, 57, 4.; 57, 5, ad 1m: “... sed etiam traductionem et promotionem usque ad perfectum statum hominis inquantum homo est, qui est virtutis status" (Sent., dist. 26, q. 1, a. 1). 
teleológica, convertidas en cauces de eleccióndecisión-operación, que hacen proceder al hombre de modo semejante y previsible en circunstancias análogas. Esta disposición estable (habitus) hace que la acción resulte "pronta", "fácil" y "deleitable" o agradable.

El contexto regulador, pues, de todo actuar es algún tipo de habitus precondicionante que impulsa y facilita las opciones de la voluntad, es decir, el ejercicio de la libertad, que no consiste en un espontáneo y azaroso brotar de actos sin dirección.

El habitus es el tamizaje del vivir. El esfuerzo que el hombre hace por alcanzar sus fines no se pierde, sino que va dejando una impronta. Esta funciona luego como derrotero para las nuevas experiencias. El habitus es la permanencia de constantes como resultado de la acumulación de experiencias anteriores. Es el pasado persistente que no se pierde en la nada, sino que acompaña el vivir actual y su proyección en el porvenir (vetera novis augere et perficere). Mediante el habitus, el hombre modifica sus sustancia, disponiéndola para seguir viviendo de manera original o singular su propia esencia humana. Aunque también esa modificación de la propia sustancia humana puede disponer en contravía de la propia esencia, en el caso de los habitus malos.

Tomás no niega la existencia de habitus en otros seres; pero privilegia al ser humano como el animal que propiamente puede $y$ debe realizarse a través de disposiciones que concreten tendencialmente su naturaleza o estructura dinámica esencial. Y señala varias condiciones para el desarrollo de esa capacidad habitual humana: a) indeterminación, receptividad, con diferentes posibilidades de realización; b) multiplicidad de facultades operativas; c) intelecto receptivo con distintas potencias susceptibles de actualizarse y combinarse; d) voluntad libre, fundada en la universalidad de la razón, con posibilidad de opción constante en determinado sentido o telos. Mientras los animales inferiores están casi determinados o adaptados, el ser humano es un ser adaptable.

El habitus tomasiano se presenta como una senda "autógena" de progreso realizativo o de regresión y degradación. Aunque tal senda puede ser trazada por exigencias de la vida social y prediseñada y fomentada por la educatio en cuanto conducción y promoción del niño, del joven, hasta alcanzar lo que se espera de la persona adulta, como complemento o determinación superpuesta a la nuda natura.

El habitus no solo es adquirido. Existen habitus innatos consistentes en disposiciones generales de la especie o de la constitución individual que son incoación o comienzos desarrollables de disposiciones elegidas o fomentadas en la convivencia. No obstante, los habitus son más resultado de los actos reiterados que de las predisposiciones evidenciadas al nacer, que pueden quedarse sin desarrollo. Los habitus operativos son engendrados, ante todo, por actos análogos y frecuentes. Tomás recuerda la metáfora de la piedra horadada por la gota repetida. Esta repetición aumenta progresivamente la profundidad y la estabilidad del habitus. La cesación de los actos análogos o sustitución por reiteración de actos contrarios, debilita el antiguo "Habitus" y origina otro de distinto signo o valor en la realización del estatuto ontológico. Esa reiteración genera cierto automatismo que nos sirve para actuar, en caso de necesidad, sobre lo que sucede repentinamente. Sin embargo, la razón puede actuar en contra de la misma costumbre consolidada por esa reiteración (Aquino, 2001).

\subsubsection{Los habitus colectivos}

Al tratar el Aquinate del bien común en cuanto valor englobante de todas las formas de coexistencia (poder, orden, paz, amistad ciudadana), subordina los habitus personales -sin negar su necesidad realizativa singular- a las exigencias de los habitus colectivos, en cuanto constantes 
operativas compartidas, que deben apuntar a la "vida buena" del todo social.

Un dinamismo moral indispensable para la vida social y política es la "justicia general" o "justicia legal", que busca dar lo suyo a la colectividad asegurando el bien común, mediante la imposición a todos los ciudadanos de pautas homogéneas de conducta intersubjetiva por medio de la promulgación y aplicación de leyes.

El habitus operativo "prudencial" (ST, II-II, 47-56), que guía el afrontamiento personal de distintos desafíos e incertidumbres situacionales, tiene su correspondiente dimensión social o política, traducida en las formas de prudencia colectiva: gubernativa, política militar, económica. La razón práctica regula las acciones de alcance supraindividual en función del sujeto colectivo. Los hábitos operativos prudenciales gobiernan los hábitos operativos de todas las dimensiones de la acción a nivel personal, pero no cuentan menos a la hora de regir los intereses del bien común colectivo y distributivo.

\section{EL HABITUS DE BOURDIEU Y SU ANCESTRO TOMISTA}

\subsection{El método semiótico en la comprensión de Bourdieu}

A partir de Charles Morris (1938), el método semiótico de comprensión de los discursos exige que todo esfuerzo hemenéutico tenga en cuenta las tres dimensiones del lenguaje: a) la dimensión semántica, que apunta a establecer las relaciones entre significantes y significados; b) la dimensión sintáctica, que se orienta a precisar las relaciones entre significantes, buscando los nexos entre las estructuras discursivas; c) la dimensión pragmática, dirigida a explicar el origen del uso que un autor 0 emisor hace de los recursos semióticos y/o sintácticos mediante los cuales expone su pensamiento y construye sus teorías.
En los apartados anteriores se ha intentado sintetizar los resultados de los aspectos semántico (propuesta sociológica de Bourdieu) y sintáctico (manera de conectar y hacer operativos sus significantes mayores). Es preciso avanzar, tratando de rastrear las influencias recibidas por Bourdieu, a fin de explicar el uso especial del lenguaje teórico del mismo, lo cual resulta útil para descubrir la riqueza de sus conceptos y categorías. No obstante, el presente ensayo no puede pretender agotar ese rastreo y tan solo se limita a procurar precisar una de las notorias influencias recibidas por Bourdieu en relación con el significante habitus, que posee centralidad en su discurso. La notoria influencia de que hablamos es la de Tomás de Aquino, reconocida en las citas que el sociólogo hace del maestro medieval y explicitada por estudiosos de su obra.

\subsection{El método del diálogo}

El diálogo filosófico es el método interactivo que expresa una intención de pensamiento no dogmático en torno a una determinada realidad o problema, en busca de consensuar enfoques y conclusiones frente a "cuestiones disputadas". Tanto Bourdieu como Tomás de Aquino son dialécticos, es decir, necesitan abrirse a todas las opiniones, tanto del pasado como de su respectiva contemporaneidad, pues uno y otro se formaron en la tradición del sic et non, que arranca con Pedro Abelardo en el siglo XII: a la verdad se accede gradualmente y no hay respuestas definitivas, sino conclusiones provisionales, acordadas por inteligencias en diálogo leales a las exigencias de la razón. Siempre habrá status quaestionis, un estado no definitivo de problematización y de respuesta.

Por ello, Bourdieu no tiene escrúpulos en buscar diálogo con Aristóteles o su discípulo Tomás, a pesar de que se trata de un diálogo transtemporal. Tampoco Tomás tenía óbice en dialogar con sujetos ausentes, de épocas y culturas distantes. Entre Bourdieu y Tomás hay "comunidad intelectual", especialmente desde el punto de vista metódico, aunque 
se dan también acuerdos teóricos, puntualmente y para los fines de este ensayo, en la noción y aplicación del tecnicismo habitus, expresión del sentido práctico para uno y otro, dinamismo para la acción en situación (prudencia), en el caso del segundo.

\subsection{Principio de clarificación}

La principal intención de todo diálogo (presencial, a distancia o transtemporal) es la dilucidación o clarificación de las ideas y de los argumentos. Bourdieu reconoce que el "principio de clarificación" fue "caro a Tomás de Aquino" (Bourdieu, 2008: 50). Este lo enuncia indirectamente en varios lugares de su obra, y a veces lo explicita, como en el prólogo de la Suma teológica, aplicado a la pedagogía ${ }^{16}$. La metodología de los artículos que desarrollan las cuestiones de la Suma teológica se proponen alcanzar máxima claritas en los términos, en las ideas, en las distinciones, en las respuestas y en los argumentos.

El "principio de clarificación" del Aquinate fue también preocupación de otros maestros escolásticos, todos convencidos de la necesidad de las "ideas claras y distintas". El principio no se quedó en la Edad Media, sino que fue recibido como clave epistemológica por la Modernidad. Destaquemos algunos hitos: Descartes, en primer lugar; Leibniz, Locke, Vauvenargues. De este último podemos retener estas frases: "Ia oscuridad es el reino del error" y "la claridad es la buena fe de los filósofos". Es tan importante el tema de la "claridad" del discurso filosófico que la metáfora de la luz sirvió para designar el siglo de la Enciclopedia, el Siglo de las "Luces" y el proceso de irradiación de la razón: llustración, o como se designó en

16 El "principio de clarificación" tomasiano, tal como aparece sugerido en el prólogo de la Suma teológica, cumplía varios propósitos de intención especialmente didáctica: a) superar el "número excesivo argumentos"; b) recuperar "el orden de la disciplina"; c) evitar la "confusión debida a las repeticiones"; d) preferir la "brevedad"; e) "poner en claro" ("dilucidare"), es decir, establecer conceptos "simples" y "distintos". alemán: Aufklärung (esclarecimiento). Más tarde, en nuestra tradición filosófica de lengua española, Ortega y Gasset insistirá: “la claridad es la cortesía del filósofo". Herederos de la misma preocupación por la claridad han sido los filósofos analíticos.

Según Bourdieu, el "principio de clarificación" sigue siendo útil hoy para que los dialogantes de diferentes épocas puedan utilizar idénticos o análogos significantes, aunque aludan a referentes más o menos distintos. Precisamente "clarificar", en este caso, consiste en reajustar el antiguo significante y su significado a las exigencias inéditas de los referentes de hoy. Bourdieu toma un tecnicismo ya consagrado por el pensamiento tomista: "habitus", y descubre que sigue vivo en el lenguaje filosófico de hoy, pero que requiere ser "clarificado" para hacerlo auténticamente contemporáneo. Lo cual implica respetar el sentido clásico, pero al mismo tiempo prolongar ese sentido para adaptarlo a las exigencias cognitivas de los fenómenos antropológicos y sociales de hoy.

\subsection{Influencias epistemológicas análogas entre Tomás de Aquino y Bourdieu}

La falta de escrúpulos en el uso de recursos técnicos o campos semánticos de filósofos de distinto origen epocal o cultural es muy semejante en Tomás de Aquino y en el sociólogo francés. Tomás había recibido la influencia formativa de Alberto Magno, quien había propuesto a los Estudios Generales dominicanos, entre ellos el de Colonia, y a la Universidad de París que una de las claves para enriquecer el conocimiento filosófico y teológico de los cristianos (en apertura católica) era abrirse a toda verdad, asimilando y articulando todas las propuestas cognoscitivas, sin desdeñar ni a griegos, ni a latinos, ni a judíos, ni a musulmanes.

Tomás aprendió de tal manera la lección de su maestro que sus obras constituyen un esfuerzo de diálogo en el que todos son invitados a aportar a la verdad -bien asumiendo el sic, bien asumiendo el non-, a las grandes preguntas 
problemáticas (quaestiones). Tomás insiste en que hay que cultivar con cuidado los gérmenes de verdad dondequiera que se encuentren, y que el proceso histórico del espíritu debe nutrirse con las invenciones de los predecesores (Com. a la Ét.). Y enfatiza que en la elección de opiniones no puede el investigador sino conducirse por la certeza de la verdad al margen de simpatías o antipatías (Com. Met.). Recalcaba que en la búsqueda de la verdad se impone escuchar a todos, de manera análoga al método de los tribunales, que escuchan las razones de las partes y toda suerte de testimonios.

En cuanto a Bourdieu, se trata de un caso semejante al de Alberto y Tomás, conducido, sin duda, por su formación filosófica y el consiguiente conocimiento del macro-diálogo de la historia de la filosofía, del cual también su maestro Gastón Bachelard había aprendido, habilitándose para fungir como el gran epistemólogo de mediados del siglo $X X$, tenido en cuenta tanto por los científicos de las ciencias naturales como por los de las ciencias humanas y sociales.

Bachelard había descubierto que una solo filosofía es insuficiente para dar cuenta de la realidad y que es necesario convocarlas a todas para articular las nociones que pueden ayudar a concretar un conocimiento particular. Bachelard se negaba a inscribir los conceptos científicos dentro de una solo perspectiva o punto de vista, y exigía una "síntesis plural" que permitiera observar como a través de un prisma, integrador de iluminaciones "complementarias".

Su discípulo Bourdieu, igualmente, se niega a encerrar sus conceptos en una sola perspectiva y procura hacerse con el bagaje histórico de las distintas filosofías, sometiendo las posibles propuestas complementarias a la prueba de su poder explicativo frente a la complejidad de la realidad social. De ahí que no pretenda presentar el habitus como paradigma nuevo y novedoso, sino que lo toma como una idea explícita presente en la tradición filosófica y moral, bien común, de uso libre por todo investigador que la descubra útil.

\section{CONCLUSIONES}

Después de este ejercicio dialógico entre Pierre Bourdieu y el medieval Tomás de Aquino, he podido convencerme de que el alcance de una doctrina filosófica depende de su poder de intervenir como interlocutora de otras formas de pensar, con las cuales puede hallar intereses temáticos comunes y aun soluciones análogas para problemas compartidos.

He tratado de seguir la sugerencia Husserl, padre de la fenomenología, quien pensaba que es de gran importancia buscar las relaciones entre distintas corrientes filosóficas, pues de esa manera una filosofía dialogante aclara su propio poder de comunicación y su valor de verdad. Si una filosofía se cierra en sí misma puede dar ocasión a prejuicios dogmáticos y a la incapacidad para auto-comprender sus límites.

Bourdieu, respecto de la capacidad comprensiva humana, postula la integración entre "inculcación" e "incorporación", es decir, entre la dotación institucional de herramientas para la vida y la incorporación de lo que la experiencia va dejando. Tomás de Aquino también considera necesaria la relación entre la disciplina y la inventio. Por disciplina el Aquinate entiende el proceso de enseñanza-aprendizaje en que existe alteridad pedagógica: el docens y el discens. Y por inventio entiende el aprendizaje natural por el mero uso de la sensibilidad, la inteligencia y la razón. Así, espontáneamente, se está aprendiendo desde el mismo nacimiento.

Sus definiciones de habitus coinciden en cuanto a que son "disposiciones difícilmente movibles", incluso en su "transferibilidad" por la educación.

Los dialogantes coinciden en que los "hábitos" preparan para la acción en momentos límite en los que es difícil la racionalización de la situación. 
Se trata de una especie de automatismos que aseguran la conservación del sujeto.

El concepto de naturaleza difiere en Bourdieu y Tomás. Para el primero, se trata de aquellas prácticas consolidadas que aparecen como necesarias y que están al principio de los esquemas de percepción y apreciación. Para el segundo, se trata de lo esencial al existente.

En Bourdieu, los habitus no son innatos, mientras que Tomás reconoce habitus innatos, como la "sindéresis".

Bourdieu no quiso definir sus categorías para que cualquier investigador las usara libremente y encontrara su significado en la interacción con su objeto de estudio. "Un libro para quemar" es prácticamente la idea que Bourdieu tiene de su obra, especialmente de aquello que tienda a dogmatizarse o a ser dogmatizado por la comunidad hermenéutica. Lo mismo pensó Tomás cuando pidió a su secretario que quemara toda su obra, porque era "paja". Estas posturas filosóficas dejan los dos sistemas abiertos.

El habitus de Bourdieu le impuso hacerse con las claves culturales de los verdaderos "herederos" del mundo universitario. Tomás pertenecía a esos herederos.

Los habitus bourdeianos tienden más hacia el hábito categorial, como se evidencia en Homo academicus, por ejemplo; mientras que para el Aquinate, la tendencia es a considerar que las cosas son buenas en sí, lo que lo lleva a dar más peso al habitus cualitativo.

Para Bourdieu, el Derecho, como norma, garantiza las posiciones dominantes dentro del campo social. Tomás, por su parte, considera que cuando la ley busca el bien particular de determinado régimen, y no el bien común, asegura la existencia de la tiranía.

\section{REFERENCIAS}

\section{Fuentes primarias bourdeianas}

Bourdieu, P. (1991). La Distinción. Criterio y bases sociales del gusto. Madrid: Taurus.

Bourdieu, P. (2002). Las estructuras sociales de la economía. Buenos Aires: Manantial.

Bourdieu, P. (2005). Elementos para una sociología del campo jurídico. En La Fuerza del Derecho. Bogotá: Universidad de los Andes -PUJA- Siglo del Hombre.

Bourdieu, P. (2008). Homo academicus. Buenos Aires: Siglo XXI.

Bourdieu, P. (2010). El sentido práctico. Buenos Aires: Siglo XXI.

Bourdieu, P. y Passeron, J.C. (1969). Los estudiantes y la cultura. Barcelona: Ed. Labor.

Bourdieu, P. y Passeron, J.C. (1977). La Reproducción. Elementos para una teoría del sistema de enseñanza. Barcelona: Ed. Laia.

\section{Fuentes secundarias sobre Bourdieu}

Giménez, G. (2000). La sociología de Pierre Bourdieu. Cuadernos de Sociología, 35: Nuevos actores/Nuevos temas. Bogotá: USTA.

Martínez, A.T. (2007). Pierre Bourdieu: razones y lecciones de una práctica sociológica. Buenos Aires: Manantial.

Moreno, Á. y Ramírez, J. (2006). Pierre Bourdieu: introducción elemental. Bogotá: Panamericana.

Moreno, Á. y Ramírez, J. (S.f.) Sociología del Campo Jurídico en Colombia. Relaciones y perspectivas. Bogotá: ILAE. 
Sánchez Horcajo, J. (1988). Sociología Interpretativa. Pierre Bourdieu. En Para comprender la teoría sociológica. Pamplona: EVD.

Vázquez García, F. (2002). Pierre Bourdieu. La sociología como crítica de la razón práctica. Madrid: Ediciones de Intervención Cultural.

\section{Fuentes primarias tomasianas}

Aquino, T.d. (1989). Suma teológica, dirigida por los Regentes de Estudios de las Provincias Dominicanas de España, t. II, Madrid: BAC.

Aquino, T.d. (2001). "Cuestiones de la sindéresis y la conciencia"; "Cuestión del libre albedrío"; "Cuestión sobre la elección humana"; "Cuestión sobre las virtudes en general". En Opúsculos y cuestiones selectas, t. II., Madrid: BAC.

Aquino, T.d. (2002). Comentario a las sentencias de Pedro Lombardo. Vol. 1 y 2, Pamplona: EUNSA.

\section{Fuentes secundarias sobre Tomás de Aquino}

Aubert, J.M. (1987). Filosofía de la Naturaleza. Barcelona: Herder.

Gilson, É. (2002). El Tomismo. Introducción a la filosofía de Santo Tomás de Aquino. Pamplona: EUNSA.
Grenier, H. (1952). Cursus philosophiae. Volumen Secundum. Metaphysica. U. Laval.

Murillo, J.I. (1998). Operación, hábito y reflexión. Pamplona: EUNSA.

Rodríguez Rodríguez, V. (2001). Introducción a las cuestiones 49 a 54. En Opúsculos y cuestiones selectas, t. II., Madrid: BAC.

Sellés, J.F. (2008). Los hábitos intelectuales según Tomás de Aquino. Pamplona: EUNSA.

\section{Otras obras citadas}

Bachelard, G. (1971). Epistemología. Antología de Dominique Lecourt. Barcelona: Anagrama.

Bachelard, G. (1984). La filosofía del no. Buenos Aires: Amorrortu.

Bachelard, G. (1994). El derecho de soñar. México: FCE.

Merleau-Ponty, M. (2003). El mundo de la percepción. México: FCE.

Morris, C. (1985). Fundamentos de la teoría de los signos. Barcelona: Paidós. 